\title{
Saúde global, inovação biotecnológica e risco(s)
}

\author{
Global health, biotechnological innovation and risk(s) \\ Salud global, innovación biotecnológica y riesgo(s)
}

Eduardo António da Silva Figueiredo ${ }^{1}$

\begin{abstract}
Resumo
Objetivo: refletir sobre o conceito de saúde global, a sua origem, sentido(s) e notas caraterizadoras. Compreender em que medida a doutrina se vem referindo a um Direito da Saúde Global, analisando quais os seus principais méritos, limitações e inconvenientes. Analisar alguns dos avanços biotecnológicos que têm aberto as portas a novas potencialidades de incrementação da saúde e do bem-estar à escala global. Metodologia: foi utilizado o método dedutivo a partir da análise de obras monográficas, artigos de revistas da especialidade, bem como de documentos emanados por diversas entidades nacionais e estrangeiras. Resultados: num contexto de crise tecnocientífica, a inovação biotecnológica, embora contribua para a melhoria da saúde global, acarreta inúmeros riscos. Cada vez mais, se tem afirmado a importância do chamado Direito da Saúde Global, o qual procura contribuir para a otimização das possibilidades de melhoria dos índices de saúde à escala global, mormente através da formulação de respostas precaucionais adequadas. Conclusão: a melhoria dos índices de saúde à escala global depende, inter alia, da inovação biotecnológica, a qual só será viabilizada através de uma adequada gestão do risco a realizar a partir do conceito de diligência devida. O Direito da Saúde Global, enquanto sub-ramo jusinternacional do Direito da Saúde, poderá dar valiosos contributos nesse sentido, não obstante as suas múltiplas limitações e dificuldades.
\end{abstract}

Palavras-chave: Saúde global. Direito à Saúde. Biotecnologia. Risco. Precaução.

\begin{abstract}
Objective: to reflect on the concept of global health, its origins, meaning(s) and main characteristics. To understand to what extent the doctrine has been referring to a Global Health Law, analyzing its main merits, limitations and inconveniences. To examine some of the biotechnological advances that have opened the doors to the possibility of increasing health and well-being on a global scale. Methodology: the deductive method was used from the analysis of monographies, articles from specialized reviews, as well as documents originating from several national and international entities. Results: in the context of a techno-scientific crisis, biotechnological innovation, although contributing to the improvement of global health, carries numerous risks. Increasingly, the importance of the so-called Global Health Law has been affirmed; it seeks to contribute to the optimization of health indices on a global scale, especially through the development of adequate precautionary responses. Conclusion: the improvement of health indices on a global scale depends, inter alia, on biotechnological innovation, which will only be made possible through an adequate risk management to be carried out on the concept of due diligence. The Global Health Law,
\end{abstract}

\footnotetext{
${ }^{1}$ Mestre em Ciências Jurídico-Políticas; assistente convidado da Secção de Ciências Jurídico-Políticas da Faculdade de Direito, Universidade de Coimbra, Portugal. E-mail: efigueiredo.1995@gmail.com
} 
understood as an international branch of Health Law, can make valuable contributions in this regard, despite its multiple limitations and difficulties.

Keywords: Global health. Right to health. Biotechnology. Risk. Precaution.

\section{Resumen}

Objetivo: reflexionar sobre el concepto de salud global, sus origines, significados y notas características. Comprender en qué medida la doctrina se ha referido a un Derecho de la Salud Global, analizando sus principales méritos, limitaciones e inconvenientes. Examinar algunos de los avances biotecnológicos que han abierto la puerta a nuevas potencialidades para la mejora de la salud y del bienestar a la escala mundial. Metodología: el método deductivo ha sido utilizado a partir del análisis de trabajos monográficos, artículos de revistas especializadas, así como de documentos emitidos por varias entidades nacionales y extranjeras. Resultados: en un contexto de crisis tecnocientífica, la innovación biotecnológica, aunque contribuya para la mejora de la salud global, conlleva numerosos riesgos. Cada vez más, se ha afirmado la importancia del Ilamado Derecho de la Salud Global, el cual busca contribuir para la optimización de las posibilidades florecimiento de los índices de salud global, especialmente a través de la formulación de respuestas precauciónales adecuadas. Conclusión: la mejora de los índices de salud global depende, inter alia, de la innovación biotecnológica, la cual sólo será posible a través de la gestión adecuada del riesgo a partir de la movilización del concepto de debida diligencia. El Derecho de la Salud Global, entendido como una rama internacional del Derecho de la Salud, puede hacer contribuciones valiosas a este respeto, a pesar de sus múltiples limitaciones y dificultades.

Palabras clave: Salud Global. Derecho a la Salud. Biotecnología. Riesgo. Precaución.

\section{Introdução: uma nova revolução em curso?}

Estamos a vivenciar a Quarta Revolução Industrial, assistindo-se ao surgimento de novas tecnologias (v.g. digitais, biotecnológicas, informacionais) e de novas formas de encarar e entender o mundo que desencadeiam disruptivas alterações nos sistemas políticos, económicos, financeiros e nas próprias estruturas sociais. Segundo Klaus Schwab, as suas ramificações são bem mais "profundas do que qualquer outro período da história humana", impactando governos, empresas, a sociedade civil e os próprios indivíduos (1).

Nesse contexto, cada vez mais, o progresso científico-tecnológico avança à velocidade da luz (porventura, demasiado rápido, deixando para trás a tartaruga ético-jurídica) e o Homo Evolutis - que tem a capacidade de projetar mentalmente o seu futuro - parece não desistir da pretensão de construir uma sociedade e um planeta à sua medida.

Aos poucos, o ser humano procura controlar o seu próprio substrato biológico, incrementando as suas capacidades físicas, psicológicas e emocionais, já não apenas por via do melhoramento de instrumentos externos, mas também pela própria "melhoria do espírito e corpo humanos, ou uma fusão direta com aqueles instrumentos" (2) - questões que, inclusivamente, 
têm feito questionar o que significa, atualmente, ser-se humano e, indo ainda mais longe, qual o estatuto, mormente ético e jurídico, que devemos reconhecer, no futuro, aos chamados transumanos - os quais apresentarão uma constituição biológica aperfeiçoada, seja pela melhoria do seu pedigree genético, seja pela fusão do seu corpo com o de outras espécies animais (o que nos remete para o problema da criação de híbridos ou quimeras) - ou aos pós-humanos surgidos da hibridação entre o homem e a máquina (os conhecidos ciborgues). Há mesmo quem, no limite, avance com tentativas - ab initio frustradas - de definir cientificamente a pessoa, como se esta não fosse uma categoria ético-axiológica, ainda que com pontes reconhecidamente ontológicas (3).

Além disso, como a própria história se encarregou de nos ensinar - a maior parte das vezes, da forma mais hedionda possível -, importa não esquecer que o avanço científico não é, nem pode ser, neutro (scilicet, inserido num vácuo desassociado de quaisquer valores morais ou sociais); antes, ele encontra-se profundamente comprometido com distintas conceções mundividenciais, diferentes premissas axiológico-valorativas e interesses políticos, económicofinanceiros, sociais e individuais heterogéneos (por vezes mesmo, conflituantes). A ciência pretende servir, portanto, a sociedade e o indivíduo, mas não partindo de uma formulação absolutamente holística que abarque todas as formas como estes se nos apresentam empiricamente (ou até, de forma bem mais complexa, num plano metafísico). Queremos com isso dizer que um determinado advento científico visará sempre servir, ao menos num primeiro momento, a específica e historicamente situada conceção ou ideologia social e/ou individual que funda e justifica a(s) escolha(s) científica(s) apoiada(s) pela comunidade ou tomada(s) pelo próprio investigador (4). Será exigível, portanto, um elevado sentido de responsabilidade a todos os membros da comunidade científica, cuja atuação se encontra, cada vez mais, sujeita a escrutínio e dependente de legitimação por via de intensa participação democrática no momento da tomada de decisões fraturantes que, em larga medida, moldam o futuro da humanidade (5).

Incumbe-nos ainda referir o conhecido e já largamente explorado dilema do duplo-uso ou dual-use dilemma, que se prende com o facto de uma mesma tecnologia poder ser utilizada, simultaneamente, para a prossecução de um conjunto de finalidades absolutamente louváveis e socialmente valorizadas, mas também para o cometimento de um conjunto de atos nefastos que colocam em causa os mais básicos e fundamentais direitos e liberdades dos indivíduos - e até, quem sabe, a própria sobrevivência da espécie humana e das demais espécies que compartilham conosco esse planeta, já hoje largamente ameaçado (6). Esse fator é, em grande parte, 
responsável pela atual frustração dos investigadores e descrença da sociedade na ciência, impondo-se a tomada de medidas urgentes de reconciliação desta com aquela, e vice-versa (7).

Por outro lado, mesmo a utilização da tecnologia para fins socialmente valorizados - como são casos exemplares a proteção da saúde, do ambiente ou do bem-estar humano - acarreta inúmeros riscos desconhecidos ou, pelo menos, incertos, obrigando os indivíduos a tomar decisões sob um véu de ignorância significativo quanto aos efeitos negativos que dela podem resultar (8) - e que hoje dificilmente conhecerão fronteiras, quer no âmbito espacial, quer temporal. Assim, o diálogo com o risco é, nos dias que correm, uma constante incontornável, geradora de profundas tensões que resultam, não raras vezes, em discursos perigosos de demonização da ciência ou, em alternativa, de total subestimação (senão mesmo omissão) tecnocrática dos seus riscos intrínsecos.

Ora, nesse sentido, iremos refletir sobre o impactante conceito de saúde global, procurando compreender a sua origem, bem como colocar em destaque o(s) seu(s) sentido(s) e as suas notas caraterizadoras fundamentais. Além disso, aproveitaremos este ensejo para analisar a evolução daquilo a que parte da doutrina jurídica vem chamando de Direito da Saúde Global, evidenciando alguns dos seus méritos, mas também certas limitações e inconvenientes. Em seguida, procuraremos analisar quais os principais avanços científicos que, no quadro da biotecnologia, têm aberto as portas a novíssimas potencialidades de incrementação da saúde e do bem-estar humano à escala global. Iremos focar-nos especialmente em algumas tecnologias genéticas de índole profilática ou terapêutica e que, pelos seus impactos revolucionários, são objeto de discussão acérrima um pouco por todo o globo. Posto isso, não deixaremos igualmente de abordar, ainda que de forma breve, a questão do risco, mais especificamente no que respeita à necessidade de se procurar encetar uma adequada gestão do mesmo, evitando-se, nomeadamente no plano jurídico, que as respostas precaucionais possam ser desadequadas ou excessivas e, desse modo, obstem à otimização das potencialidades acarretadas pelos novos avanços técnico-científicos para a melhoria dos índices de saúde à escala global.

Em termos metodológicos, note o leitor que, ao longo da presente investigação, recorreremos ao método dedutivo a partir da análise de obras monográficas, artigos de revistas da especialidade, bem como de documentos emanados por diversas entidades nacionais e estrangeiras. Mais do que dar respostas, procuraremos levantar questões que permitam à comunidade académica (e à sociedade em geral) refletir sobre alguns dos desafios hercúleos com que esta Quarta Revolução Industrial nos brindará. 


\section{Saúde global: uma brevíssima análise por referência à Agenda 2030 para o Desenvolvimento Sustentável da Organização das Nações Unidas (ONU)}

A saúde é uma necessidade básica, objetiva, histórica e generalizável de todo o ser humano (9). São inúmeros os ordenamentos que a reconhecem como um verdadeiro bem jurídico, inclusive ao nível constitucional, tutelando-o por via do reconhecimento de direitos e/ou da imposição de deveres de proteção.

Por nossa parte, não nos parece despicienda a distinção entre saúde individual e saúde pública. Se a primeira nos remete para um status do indivíduo (que o preâmbulo da Constituição da Organização Mundial de Saúde [OMS] designa, de forma algo utópica, de "completo estado de bem-estar físico, mental e social, e não a mera ausência de doença ou enfermidade"), já a segunda não se basta com a simples soma das saúdes individuais, remetendo-nos antes para o conjunto de "condições que, de acordo com o desenvolvimento tecnológico e científico de cada época, garantem um nível de bem-estar, físico e psíquico, à generalidade das pessoas" (10). Subjacente a essa última conceção está, portanto, a análise do "papel do Estado e da sociedade civil na promoção da saúde e prevenção da doença" num determinado contexto histórico e geográfico delimitado (11).

Inicialmente, as ações de cariz internacional levadas a cabo no domínio sanitário apresentavam um caráter relativamente circunscrito, limitando-se a evitar a propagação alémfronteiras de certas doenças infectocontagiosas (12).

Hoje em dia, o conceito de saúde global remete-nos para um campo de atuação muito mais vasto, emergido, no essencial, da comunitarização e considerável internacionalização das preocupações de melhoria dos níveis gerais de saúde, de combate às iniquidades no acesso a serviços sanitários e a medicamentos, de proteção e preservação do meio ambiente e de prestação de cuidados de saúde em países desfavorecidos, que se encontrem em situação de emergência ou de conflito armado (13). Assim sendo, os seus ecos fazem-se sentir, de forma especial, no domínio da saúde pública (embora sejam igualmente evidentes as suas inúmeras repercussões no quadro da saúde individual).

Essa evolução (ou, se quisermos, expansão) do conceito de saúde global é fruto da globalização - ou, como bem pontua Boaventura de Sousa Santos, das globalizações (14) -, a qual nos brinda com um novo "espaço-velocidade, ao tornar supérfluas as descontinuidades geográficas, colocando todos os lugares à mesma distância-velocidade" (15). Alguns fenómenos - como as alterações climáticas, o escalar das ameaças à paz e ao desenvolvimento, a utilização 
de novas tecnologias, a internacionalização das trocas comerciais e do consumo, a deslocação de grandes massas populacionais um pouco por todo o globo ou a transformação dos estilos de vida (os quais se encontram, paradoxalmente, cada vez mais estandardizados) - têm contribuído para o desvanecer das fronteiras clássicas entre saúde no plano nacionale saúde no plano global. Os seus profundos impactos económicos, políticos, tecnológicos, culturais e ambientais colocam, pois, novíssimos desafios à saúde humana e planetária que só podem ser enfrentados por via de uma cooperação multilateral efetiva e promotora de equidade (16).

Atualmente, a doutrina tem identificado duas abordagens distintas no que respeita ao modo como a saúde global tende a ser encarada: por um lado, há quem parta de uma compreensão desta enquanto bem social e juridicamente reconhecido como valioso, que deve ser protegido, promovido e efetivado por meio de um conjunto de atuações orientadas por valores de justiça social, equidade e solidariedade entre os Estados à escala planetária; por outro lado, há quem utilize a saúde global como uma "ferramenta para viabilizar interesses [específicos] de países mais preocupados com a sua própria segurança sanitária, em aspetos transfronteiriços, militares, económicos e comerciais" (17). Essa última abordagem afigura-se bastante problemática, porque se encontra, não raras vezes, profundamente manchada por interesses egoísticos de alguns Estados que, por via da instrumentalização de diferentes mecanismos de cooperação e solidariedade internacionais, se limitam a promover a saúde dentro das suas próprias fronteiras, legitimando discursos que redundam na defesa inaceitável de uma saúde global apenas para alguns.

Além disso, gostaríamos de destacar o necessário pendor multidisciplinar das abordagens e atuações que são levadas a cabo nesse domínio - as quais surgem, na grande maioria das vezes, na intersecção entre diferentes disciplinas. Está suficientemente comprovado que um modelo exclusivamente científico-biológico, que ignore as diferentes idiossincrasias políticas, económicas, sociais e culturais de cada região do nosso globo e de cada uma das suas complexas sociedades, não poderá afirmar-se como adequado para a resolução dos desafios sanitários de geometria variável que vão emergindo à escala global (17).

A Agenda 2030 da ONU, criada em 2015, estabeleceu 17 Objetivos de Desenvolvimento Sustentável (na terminologia anglo-saxónica, Sustainable Development Goals) a fim de "erradicar a pobreza e criar uma vida com dignidade e oportunidades para todos, dentro dos limites do planeta" (18). Destacamos, hic et nunc, o terceiro objetivo, intitulado Saúde de Qualidade, o qual pressupõe, inter alia, que se atinja a chamada cobertura universal de saúde, o acesso a serviços 
de saúde básicos de qualidade, o desenvolvimento e disponibilização de medicamentos e vacinas essenciais, bem como o reforço da capacidade de todos os países, em particular dos países de baixa-renda, para o alerta precoce, a redução de riscos e a gestão de riscos nacionais e globais de saúde (19).

Já em 2016, a Declaração de Shangai, resultante da 9a Conferência Global sobre a Promoção da Saúde, veio reconhecer que a saúde e o bem-estar humano devem constituir o centro dessa agenda global destinada a alcançar o desenvolvimento sustentável. Nesse sentido, esta foi reafirmada como um direito universal, um objetivo social compartilhado e uma verdadeira prioridade política para todos os Estados (20), os quais devem promover a satisfação de "necessidades básicas de sobrevivência" - como o bom funcionamento dos sistemas de saúde, a existência de condições mínimas de higiene sanitária, o acesso a água potável e a alimentos não contaminados, a disponibilização de produtos e serviços seguros (pressupondo uma adequada gestão do risco), o acesso à vacinação e a medicamentos essenciais (11).

Recentemente, identificaram-se como principais desafios à saúde global, inter alia, o agravamento da poluição atmosférica e das alterações climáticas, a elevada incidência de doenças não-transmissíveis (como a diabetes, o cancro ou as doenças cardiovasculares), a proliferação de ambientes em estado de crise prolongada (principalmente nos denominados Estados-frágeis, i.e. aqueles que se encontram em situação de conflito ou de pós-conflito) e onde os serviços de saúde são absolutamente insuficientes e precários, o aumento da resistência aos antibióticos, a insistência na não vacinação, assim como o escalada da dengue e do HIV (21).

Como se pode ver, o caminho a percorrer é ainda bastante longo e não será feito sem dificuldades. Impõe-se, pois, que utilizemos, de forma cooperada e solidária, todos os meios (humanos, económicos, científico-tecnológicos) de que dispomos para lograr alcançar esses objetivos, permitindo a todo o ser humano usufruir do mais elevado nível de saúde possível.

\section{A emergência de um Direito da Saúde Global?}

\section{Algumas delimitações conceituais}

Inicialmente, a saúde surgia como um "bem de natureza meramente individual, cuja promoção não [cabia] à comunidade política organizada" (12). Foi o caráter comunitário de certos fenómenos de doença ( $v . g$. as epidemias) e o estabelecimento de uma conexão clara entre o estado de saúde das populações e as condições de salubridade do espaço público que contribuíram para a comunitarização deste bem, passando a incumbir-se o Estado da 
manutenção da "ordem pública sanitária" (12) - o que não deixa de nos remeter para o chamado "direito de polícia sanitária" (22).

Por sua vez, já durante o séc. XX, o surgimento do Welfare State veio alargar a intervenção pública neste domínio, responsabilizando-se o Estado pela promoção da saúde - aqui entendido como um "superdescritor" (23) - das suas populações e, progressivamente, da própria saúde global (12). Se, numa primeira fase, as medidas tomadas nesse último domínio foram relativamente tímidas e pouco impactantes, hoje em dia, são identificáveis inúmeros atores - de natureza estadual e não estadual - que adotam importantes medidas para a promoção da mesma.

Como referem Lawrence Gostin e Allyn Taylor, foi o processo de globalização que veio reforçar a necessidade de criação de novos mecanismos de governança no quadro da saúde global (11). Nesse sentido, têm-se destacado os contributos (diretos ou indiretos) de um conjunto de atores internacionais, emergidos já depois da fundação da ONU em 1945, como é o caso da OMS, da Organização das Nações Unidas para Alimentação e Agricultura (FAO, em inglês), da Fundo das Nações Unidas para a Infância (Unicef, em inglês) , da Organização Internacional do Trabalho (OIT), do Fundo Monetário Internacional (FMI) ou do Banco Mundial. A esses, acrescem variadíssimos atores de natureza não-estadual (v.g. empresas multinacionais e parcerias públicoprivadas), os quais têm o poder de influenciar, de forma cada vez mais veemente, as políticas nacionais e internacionais na matéria (13).

No plano jurídico, a doutrina tem-se referido à emergência de um Direito da Saúde Global, também apelidado por alguns autores de Direito Internacional da Saúde, embora este último nos remeta para uma abordagem mais tradicional da questão (13). Segundo Lawrence Gostin, este abrange o conjunto de "normas jurídicas, processos e instituições necessárias para a criação de condições favoráveis a que as populações de todo o mundo possam alcançar, na medida do possível, o mais elevado nível de saúde física e mental" (24).

De forma bastante ampla, podemos dizer que o direito da saúde global se afirma como um direito misto (ou um direito interdisciplinar ou transversal [12]), que se encontra no cruzamento entre direito público e privado (22) - direito constitucional, direito internacional, direito civil, direito administrativo, direito penal -, abarcando um conjunto de normas que, de forma direta ou indireta, contribuem para a melhoria do nível de saúde física e mental das populações e dos indivíduos note-se que, em última instância, a proteção e promoção da saúde no plano interno sempre contribuirá para uma melhoria da saúde à escala global (embora tenhamos de admitir que essa 
leitura pode, em certos casos, afigurar-se claramente redutora e até mesmo equivocada). Parece, pois, que, de acordo com essa formulação lata, o direito da saúde global se confunde com o ramo - bem mais delimitado e autonomizado do ponto de vista jurídico-dogmático - do direito da saúde (25), o que pode afigurar-se problemático.

Se optarmos, porém, por uma abordagem mais estrita, enquadraremos aqui apenas aquelas normas que, à escala internacional ou supranacional, prosseguem esse mesmo desiderato. Note-se, porém, que são raros os autores que se referem ao direito da saúde global (stricto sensu considerado) como um ramo jurídico autónomo ou mesmo como um ramo específico do direito internacional público $(13,22)$; antes, ele corresponde à dimensão jusinternacional do direito da saúde, afirmando-se, nessa medida, com um sub-ramo do mesmo - 0 que, a nosso ver, não nos parece ser uma maneira desadequada de o situar no quadro dos saberes jurídicos. Por razões sistemáticas (e não só), será essa a abordagem que, para efeitos da presente investigação, iremos mobilizar.

\section{Algumas fontes do "Direito da Saúde Global"}

Do ponto de vista das suas fontes, o direito da saúde globalé constituído, maioritariamente, por um conjunto de convenções internacionais que se espraiam por áreas tão diversas como os direitos humanos, o direito humanitário (mormente no que respeita à necessária proteção dos indivíduos contra o uso de armas biológicas, químicas ou nucleares), a proteção ambiental e os direitos dos pacientes (26). Todos eles têm em comum o facto de colocarem em destaque a responsabilidade dos Estados pela manutenção e/ou melhoria do nível de saúde das suas populações, bem como pelo cumprimento das suas obrigações de cooperação sanitária com outros Estados, organizações e demais atores jurídico-internacionais de relevo (11).

Destacamos, no quadro da OMS, a chamada Convenção Quadro para o Controlo do Tabaco (2003) ou o Regulamento Sanitário Internacional (datado de 1951, tendo sido profundamente revisto em 1969 e 2005), identificando, inter alia, um conjunto de procedimentos necessários à avaliação da saúde pública num contexto transfronteiriço. Bastante interessante é, ainda, a estratégia da OMS para o controlo da gripe no mundo (pandemic influenza preparedness), a qual pode ser qualificada como um instrumento jurídico híbrido: estamos ante verdadeiro soft law (e, portanto, desprovido de força jurídica vinculativa), mas que tem o potencial de criar obrigações jurídicas por via de acordos assinados no âmbito do bem-sucedido Global Influenza Surveillance and Response System (GISRS). Por fim, cabe uma brevíssima referência 
a um conjunto de recomendações - como o Código Internacional de Marketing de Substitutos de Leite Materno (1981) ou o Código de Prática de Recrutamento Internacional de Profissionais de Saúde (2010) - cuja considerável força normativa tem levado os Estados a adotar várias medidas que vão de encontro ao seu conteúdo (27).

Por sua vez, no quadro do chamado Direito Internacional dos Direitos Humanos, destacamos o art. 25ํ da Declaração Universal dos Direitos Humanos (DUDH, 1948) ou, de forma mais significativa, 0 art. $12^{\circ}$ do Pacto Internacional sobre os Direitos Económicos, Sociais e Culturais (PIDESC, 1966), bem como o Comentário Geral n 14, emanado pelo Comité dos Direitos Económicos, Sociais e Culturais, que identificou e conferiu densidade às quatro dimensões essenciais do direito à proteção da saúde: disponibilidade, acessibilidade, aceitabilidade e qualidade.

Cabe ainda referir, dessa vez no plano (pan-)europeu, o art. 11ํ da Carta Social Europeia (CSE,1996), o art. 35ํ da Carta dos Direitos Fundamentais da União Europeia (CDFUE, 2000), bem como várias normas da Convenção para a Proteção dos Direitos do Homem e da Dignidade do Ser Humano face às aplicações da Biologia e da Medicina (CDHB, 1997) ou da Convenção Europeia dos Direitos Humanos (CEDH, 1951), ambas emanadas pelo Conselho da Europa. No

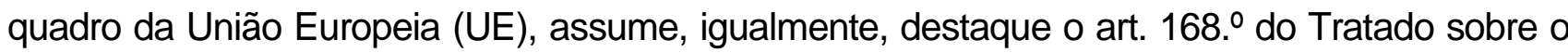
Funcionamento da União Europeia (TFUE), o qual dispõe, de forma geral, que na "definição de todas as políticas e ações da União será assegurado um elevado nível de proteção da saúde". Como pontuam Maria João Estorninho e Tiago Macieirinha, a competência da União nesse domínio serve, essencialmente, como instrumento de apoio e complementação das políticas estaduais - embora seja verdade que, cada vez mais, se tem expandido e adquirido novas vestes (12).

Na maioria desses documentos, denote-se que o direito à proteção da saúde é formulado como um direito com uma dimensão tipicamente prestacional ou positiva (que incumbe os Estados de tomarem medidas, sob a forma de políticas públicas, destinadas à prevenção da doença e seu tratamento), mas também uma dimensão negativa (traduzida na possibilidade de se exigir do Estado ou de terceiros que se abstenham de praticar quaisquer atos que possam ser considerados prejudiciais à saúde) (28).

É evidente que a realização dessa dimensão prestacional se encontra dependente de um conjunto de dimensões fáticas, económicas e sociais, impondo, num quadro de escassez, que o legislador, dentro da sua margem de conformação, leve a cabo algumas escolhas quanto ao modo 
como os recursos devem ser alocados (o que, há que admiti-lo, nem sempre é realizado da forma mais racional e eficiente). Ainda assim, não devemos deixar de reconhecer a existência de um núcleo essencial do direito à proteção da saúde que tem de ser, necessariamente, satisfeito (12, $23,29)$.

Hodiernamente, colocam-se, nessa seara, um conjunto de novos desafios, como os problemas da redefinição crescente do conceito de saúde - que se tem subjetivizado, confundindo-se com pretensões hedonísticas, o que faz com que os indivíduos exijam cada vez mais (quer quantitativa, quer qualitativamente) de sistemas de saúde já largamente debilitados (30) - ou da regulamentação da questão do acesso aos cuidados de saúde, mormente graças ao aumento, num mundo sem fronteiras, dos casos de turismo médico (31).

Além disso, tenha-se em conta que, atualmente, a efetivação dessas duas dimensões não onera exclusivamente os entes estaduais, mas também um conjunto de outras entidades e stakeholders (como os profissionais de saúde, as famílias, as comunidades locais, as organizações inter- e não-governamentais, a sociedade civil, e alguns atores de natureza empresarial), falando-se de uma responsabilidade partilhada (13).

Em alguns casos, a tutela desse bem jurídico é assegurada igualmente por via do reconhecimento de deveres (verdadeiramente jurídicos), os quais tendem a levantar alguns problemas do ponto de vista jurídico-dogmático que não iremos, hic et nunc, tratar. No quadro temporal, alguns desses diplomas vão além da mera tutela das gerações presentes, abraçando também a proteção da saúde das gerações futuras (23). Em última instância, o seu objetivo é o de permitir a todos os indivíduos, se quisermos recorrer à terminologia de Martha Nussbaum e Amartya Sen, ter a mesma capacidade (capability) para atingir um elevado nível de saúde e, assim, se autorrealizar (32).

Note-se ainda que, fruto da interdependência própria de todos os direitos humanos, são reconhecíveis um conjunto de fortes conexões - ainda que em planos distintos - entre o direito à proteção da saúde e outros direitos fundamentais e humanos, como é o caso do direito à vida, à integridade física, a um meio ambiente sadio, à informação ou à educação (13).

Por fim, cabe-nos destacar que, pelo menos de forma indireta, também o Acordo sobre os aspetos relativos aos direitos de propriedade intelectual (o conhecido Acordo TRIPS), da Organização Mundial do Comércio (OMC), pode ser incluído no elenco das fontes deste "Direito da Saúde Global" (24). 


\section{Méritos, desafios e dificuldades}

Apesar dos inúmeros méritos reconhecíveis a esse sistema internacional e supranacional de normas jurídicas destinadas a promover e efetivar a saúde física e mental dos vários indivíduos e sociedades à escala global, a verdade é que não podemos deixar de referir alguns dos relevantes desafios e dificuldades a enfrentar. E note-se, na grande maioria dos casos, esses não são novos, levando-nos a revisitar os já conhecidos territórios tortuosos dos limites da aplicação e efetivação das normas de direito internacional.

Desde logo, na maior parte das vezes, a aplicação dessas normas está, em larga medida, dependente da boa-vontade dos entes estaduais. Há casos em que chegam mesmo a recusar a assunção de certas obrigações no plano jurídico-internacional, procedendo à não ratificação seletiva de alguns diplomas internacionais ou estabelecendo inúmeras reservas ao seu conteúdo, aceitando apenas a vinculação a normas dotadas de escassa força jurídico-normativa (11). Tal deve-se, em parte, ao facto de os Estados demonstrarem uma grande resistência à delegação dos seus poderes de autoridade no domínio sanitário aos vários atores internacionais (24).

Existem também casos em que os entes estaduais, ainda que ratificando as várias convenções internacionais ou revelando abertura ao cumprimento de certas recomendações, o fazem de uma forma meramente simbólica, com a intenção última de caírem nas boas graças da comunidade internacional, mas sem que tencionem adotar as medidas necessárias à execução e efetivação do seu conteúdo (13). É exemplo de uma tal realidade a relutância que, na prática, os países de alta renda (essencialmente preocupados com a liberalização das trocas) têm demonstrado no que respeita ao fornecimento de financiamento e outros apoios aos países de baixa renda para os ajudar na promoção do seu nível de desenvolvimento, nomeadamente no quadro da saúde (24).

Por outro lado, a monitorização do comportamento dos Estados tem-se revelado altamente deficitária, seja pela falta de mecanismos adequados de vigilância sanitária, seja pela recusa dos Estados (por vezes mesmo em violação direta de normas constantes de diplomas internacionais a que estes se vincularam) na divulgação de certos relatórios cujos resultados possam apresentar reflexos negativos no plano económico-financeiro, nomeadamente por via da diminuição do investimento estrangeiro no país (26).

A temerária falta de harmonia e de coerência regulatória no seio de um campo tão amplo e que alberga fontes plurais e de naturezas tão diversas - o que tem sido agravado pela intervenção exponencial de um conjunto vasto de instituições e organizações com objetivos tão 
variados (13) -, bem como o recurso excessivo a standards vagos e a conceitos indeterminados, deixando-se aos Estados uma grande margem de manobra (porventura, demasiado extensa), afiguram-se, igualmente, como limitações claras, as quais aprofundam as já crónicas dificuldades no processo de responsabilização dos Estados pelo desrespeito - por ação ou omissão - dessas normas. Inclusive nos casos em que estamos ante diplomas consagradores de direitos humanos, os quais apresentam uma natureza jurídica verdadeiramente vinculativa (não constituíssem esses verdadeiro jus cogens), tem-se colocado a questão de saber como reagir nas situações em que os entes estaduais não cumprem (ou deixam de cumprir com) as suas obrigações jurídicointernacionais de proteção e promoção da saúde das suas populações devido a uma total incapacidade económico-financeira, política, tecnológica ou até mesmo socio-conjuntural de o fazer (11). Resta saber, nesse contexto, em que medida os demais Estados ficam vinculados pelos seus deveres de cooperação e solidariedade internacionais, os quais, a nosso ver, tendem a afirmar-se, na prática, como um mero law in the books.

\section{Inovação biotecnológica, genética e saúde}

Em termos bastante amplos, pode afirmar-se que a biotecnologia abrange um conjunto de processos e produtos que oferecem o potencial de alterar e, em certa medida, de controlar o fenómeno da bios (da 'vida'). Num plano maioritariamente conceitual e ético, a mesma afirma-se como uma expressão do espírito tecnológico, de um desejo e disposição racional de compreender, predizer e, eventualmente, controlar os eventos e obras da natureza, com a finalidade última de beneficiar o ser humano (33).

Do mesmo modo, há quem se refira ao desenvolvimento de uma biotecnociência, que valoriza a "ação concreta, por meio de técnicas e dispositivos, sobre problemas" (34), afirmandose como o resultado de vários progressos no campo biológico, nomeadamente no quadro da biologia molecular, da bioquímica, da genética, das neurociências ou da nanotecnologia (34).

Iremos, hic et nunc, referir-nos exclusivamente aos principais avanços científicos na área da genética que contribuem (ou que têm o potencial de contribuir), direta ou indiretamente, para a promoção da saúde global, chegando mesmo, em certos casos, a transformar os atuais paradigmas e modelos em que repousam os atuais sistemas de saúde.

Desde o término do Projeto do Genoma Humano (em 2003), que culminou com o mapeamento e sequenciação do genoma humano, tem-se assistido ao aumento exponencial do conhecimento sobre as várias doenças genéticas, bem como os genes nelas implicados (35). Tal 
facilitou, como é evidente, o desenvolvimento de novas terapêuticas, assim como de novos instrumentos que poderão ser utilizados na prevenção e diagnóstico deste tipo de enfermidades - como é o caso dos testes genéticos, os quais são cada vez mais fiáveis, precisos e económicos, tornando "possível prever (antes mesmo de aparecer qualquer sintoma) a ocorrência de (...) ou a predisposição para uma determinada doença genética, no indivíduo a quem o teste é realizado" (36). Acontece que, ao contrário dos testes genéticos clássicos (baseados no estudo individual de cada gene), os testes genéticos de nova geração analisam, de forma sequencial, "segmentos do genoma, quer levando a cabo uma análise global do mesmo, quer de alguns segmentos importantes para a identificação ou confirmação do diagnóstico de uma doença genética" (37). Assim, torna-se possível a tomada de medidas profiláticas ou o início antecipado (ou, pelo menos, atempado) da terapia, impedindo-se o aparecimento da doença ou, pelo menos, retardando-o.

Por outro lado, a identificação das mutações genéticas responsáveis por certas doenças hereditárias, abriu as portas à possibilidade de elaboração de uma "nova forma de terapia na qual o ADN é o medicamento" (38) - fala-se, a esse propósito, da chamada terapia génica, hoje em dia levada a cabo através da mobilização de técnicas tão variadas como as ZFNs, as TALENs e a CRISPR/Cas (39). A discussão tem sido, aliás, bastante polémica no que respeita à admissibilidade ético-jurídica da edição da linha celular germinal para fins preventivo-terapêuticos, a qual permite (não sem consideráveis riscos) a erradicação intergeracional de algumas doenças genéticas nefastas (39). Indo mais longe, há mesmo quem diga que será possível editar os genes com vista ao melhoramento das caraterísticas físicas e psicológicas individuais, dando lugar ao surgimento de super-homens (a transumanos) e à total transformação (senão mesmo destruição) das hodiernas estruturas sociais (40).

É nesse contexto de progresso técnico-científico no âmbito da saúde, mormente no campo da genética clínica, da proteómica e da farmacogenómica, que se tem vindo a promover a implementação - ainda mais desejada, que efetiva - de um modelo sanitário personalizado (falase de uma medicina personalizada de precisão) que prime, por um lado, por um discurso profilático e, por outro lado, pela elevada eficácia e segurança dos tratamentos médicofarmacológicos a aplicar. A transição para um tal modelo, não obstante as suas potencialidades, nunca deverá ser levada a cabo sem que sejam tomadas em conta as múltiplas limitações técnicas, económico-financeiras, sociais e pessoais à sua implementação e as suas respetivas repercussões no campo jurídico (41). 
Podíamos ir mais longe e mencionar outros avanços científicos que, ainda no âmbito biotecnológico, têm procurado contribuir para a melhoria dos níveis de saúde dos indivíduos e das populações (como é o caso da nanomedicina, da investigação e utilização de células estaminais, etc.). Estamos em crer, porém, que essa pequena amostra que, hic et nunc, apresentámos (ainda que de forma muito breve) já é, per se, suficientemente elucidativa do modo como o ser humano tem procurado colocar a ciência ao serviço da vida e da saúde, desenvolvendo mecanismos que permitam a todas as pessoas, as de hoje e as de amanhã, autorrealizar-se em toda a sua plenitude.

Ainda que grande parte desses progressos sejam oriundos dos chamados países de elevada-renda - os quais são dotados de mais e melhores recursos humanos, técnicos e económico-financeiros -, não podemos ignorar a existência de casos em que foram os países de baixa-renda a dar o seu contributo significativo para o desenvolvimento de novos processos, intervenções e sistemas, nomeadamente no quadro da saúde - é aquilo que alguns autores chamam de inovação reversa. Por isso é que é tão importante, e não nos cansamos de o afirmar, que se promova uma verdadeira cooperação entre os vários entes estaduais à escala global (desde os mais desfavorecidos, aos mais ricos), devendo esses encarar aqueles não apenas como futuros consumidores, mas antes como entidades que, dentro das suas possibilidades, poderão desempenhar um importantíssimo papel no processo de inovação sanitária (42). Do mesmo modo, e porque a inovação só contribuirá verdadeiramente para a promoção da saúde global se estiver ao alcance de todos, é importantíssimo que os vários Estados se revelem solidários, mormente através da partilha de benefícios resultantes de qualquer investigação científica, bem como das suas aplicações. Assim, a dimensão coletiva da liberdade de investigação científica tem, a nosso ver, de ser levada a sério, prevalecendo sobre interesses meramente económicos e colocando, de forma efetiva, a ciência ao serviço de toda a humanidade.

\section{Um diálogo constante e incontornável com o risco}

No antropoceno, o risco assume-se como "predicado nuclear das científico-tecnicamente polarizadas e económico institucionalmente complexas sociedades contemporâneas integradas no nosso arco civilizacional" (43), apresentando novos contornos e afirmando-se como uma das principais ameaças à qualidade de vida e, até mesmo, à sobrevivência das espécies. 
Foi na década de 80 do século passado que, no seguimento do discurso em torno da chamada sociedade técnica de massas, o grande motivo condutor passou a ser a "sociedade de risco" (44). O fenómeno da globalização e o aumento considerável do avanço científicotecnológico contribuíram para a exponenciação dos riscos da ação humana, hoje marcada por uma clara transterritorialidade e transtemporalidade que abrem portas a crises intra- e intergeracionais que fazem da vida em sociedade uma autêntica "experiência-limite, em que se toma consciência dos limites da Modernidade" (45). O seu estudo tem sido levado a cabo no quadro da chamada riscologia, enquanto conjunto de ciências que se dedicam ao estudo do risco (46).

Todos os avanços no quadro da chamada biomedicina, tal como relembra João Loureiro, ao mesmo tempo que atenuam a fragilidade e a vulnerabilidade biológicas, desencadeiam novas feridas no nosso ser (22), contribuindo para que as expetativas comunitárias oscilem entre o "otimismo ingénuo e serôdio da Modernidade e [um] novo obscurantismo apocalíptico" (47). Cada vez mais, a questão do risco deixa de se compadecer com uma mera racionalidade técnicocientífica, exigindo uma ponderação verdadeiramente valorativa e normativa, mormente no que respeita à alocação estratégica de recursos para evitar a materialização de uma qualquer catástrofe (48).

Atualmente, o princípio da precaução tem-se afirmado como verdadeiro princípio reitor e orientador das entidades públicas na investigação, avaliação e, essencialmente, na gestão do risco (10). A sua aplicação verifica-se naqueles casos em que um determinado "fenómeno, produto ou processo acarretam riscos graves, mas cuja avaliação científica não nos permite determiná-los, com suficiente certeza, quer qualitativamente, quer quantitativamente” (49). Ora, no campo da genética (e da biotecnologia em geral), os riscos, além de graves, são incertos (principalmente quanto à sua verificação e à sua gravidade), não havendo forma de saber se a mesma contribuirá para tornar mais aprazível a vida em sociedade ou se os seus já identificados riscos biológicos, demográficos, sociais e económicos poderão conduzir a autênticas catástrofes (50).

Alguns autores defendem que o princípio da precaução justifica a total proibição do recurso a essas técnicas (mesmo para fins preventivo-terapêuticos) ou, pelo menos, a aprovação de uma moratória internacional que paralise temporariamente a sua utilização. Tais soluções afiguram-se desadequadas e simplesmente representam uma sucumbência do ser humano à heurística do medo, devendo sempre ter-se em consideração que o risco-zero, especialmente no quadro da saúde, é uma total ficção. 
Assim, o discurso bicéfalo entre técnica e risco encontra-se profundamente ultrapassado, devendo dar lugar ao confronto de distintos riscos: o risco de levar a cabo um determinado procedimento ou de aplicar uma técnica específica face ao risco de não o fazer. Será sempre necessário, portanto, que se corram riscos, colocando-se apenas a questão de saber quais são aceitáveis e até que ponto o devem ser (39).

Como já defendemos em outros momentos, tal implicará um respeito escrupuloso por um conjunto de regras materiais e procedimentais de diligência devida, bem como uma cuidada análise casuística dos potenciais custos e benefícios de cada intervenção. Nesse sentido, sempre haverá que ser considerada a gravidade das doenças que esperamos prevenir ou tratar, a existência de terapias alternativas que sejam científica, social e eticamente preferíveis, bem como a existência (ou não) de registos de consequências negativas a curto, médio ou longo prazo decorrentes da utilização dessas mesmas técnicas. Garantir a qualificação dos próprios profissionais, a devida monitorização ou fiscalização de todo o processo por órgãos competentes e independentes, a prestação do consentimento esclarecido, bem como o respeito por todos os direitos e liberdades dos indivíduos colocados em cheque são outros dos passos que garantem uma resposta precaucional adequada - uma resposta que, como se vê, não ignora o risco, mas tampouco se deixa dominar por ele (39).

Estamos, pois, conscientes de que uma qualquer decisão precaucional sempre acarretará riscos, desde logo aqueles que resultam de uma aversão inflexível aos mesmos - o que, não raras vezes, redunda numa limitação dos próprios direitos e liberdades fundamentais dos indivíduos em nome de uma afirmação absoluta do valor da segurança (48). Devemos, pois, recorrer a uma "estratégia de pequenos passos" (51), procurando que esses nos permitam, no futuro, alcançar um estado de desenvolvimento técnico que reduza o risco a níveis científica e socialmente aceitáveis e, assim, permita a utilização das várias biotecnologias para a promoção da saúde à escala global.

\section{Conclusão}

Feitas estas (breves) considerações sobre as temáticas da saúde global, da inovação biotecnológica e da gestão do risco, cremos ter logrado colocar em evidência as distintas e heterogéneas relações que é possível estabelecer entre as mesmas. Não raras vezes, tais afinidades desaguam em tensões e conflitos de dificílima resolução porquanto, muito embora a inovação biotecnológica (aliada a outros fatores, é certo) possa contribuir, de forma efetiva, para 
a melhoria dos índices de saúde à escala global, a verdade é que os seus riscos (na maioria das vezes, ainda incertos) podem, igualmente, despoletar novas feridas que evidenciem (ou aprofundem) as vulnerabilidades de um ser humano, já per se, frágil.

Num primeiro momento, demos conta de alguns dos desafios da ciência na Quarta Revolução Industrial, nomeadamente a superação do mito da sua neutralidade, compreendendose que o avanço científico surge comprometido com uma particular conceção do mundo, da sociedade e dos indivíduos. Por outro lado, manifestámos a nossa preocupação para com o modo como o dilema do duplo-uso, assim como um certo discurso científico-societário maquiavélico (que ora demoniza, ora santifica - sempre de forma redutora - o progresso científico) têm quebrado a confiança da sociedade na ciência, e vice-versa. Todo esse quadro surge agravado com a ascensão dos chamados tecnocratas, cujo discurso se centra irremediavelmente no clássico imperativo tecnológico - o qual propugna que se é possível conceber determinada tecnologia, ela será, de forma inevitável, desenvolvida e utilizada (4).

Em seguida, abordámos o conceito de saúde global, o qual tem, com o aprofundamento do(s) processo(s) de globalização, ganho cada vez mais autonomia e densidade dogmática (principalmente face aos conceitos de saúde individual e de saúde pública). Esse remete-nos, sempre a partir de uma abordagem multidisciplinar, não só para uma certa comunitarização e internacionalização das preocupações de melhoria dos níveis gerais de saúde, mas também para problemas, inter alia, de justiça distributiva, equidade ou justiça ecológica.

É nesse contexto, aliás, que parte da doutrina jurídica se tem referido a um direito da saúde global, o qual deve ser encarado, a nosso ver, como um sub-ramo do já muito explorado direito da saúde. A esse propósito, fizemos referência a algumas das fontes jus-internacionais que o compõem e à sua diversidade (quer quanto à sua origem, matéria, natureza jurídica ou força normativa), bem como a vários dos seus méritos, mas também das suas limitações e dificuldades.

Além disso, para aclarar as conexões entre inovação biotecnológica e saúde global, propusemo-nos fazer uma brevíssima referência a algumas das mais recentes conquistas no quadro da genética - e que tornam patente que vivemos, atualmente, uma verdadeira Revolução Genómica. Nesse sentido, mencionámos os chamados testes genéticos de nova geração, os diferentes e revolucionários avanços no quadro da engenharia genética, bem com alguns progressos no quadro da proteómica, da genética clínica e da farmacogenómica, os quais têm alavancado a implementação de uma medicina personalizada de precisão, que ousa colocar em causa dos clássicos paradigmas que, hodiernamente, sustentam os nossos sistemas de saúde. 
Todos esses avanços têm em comum a possibilidade de facilitar a prevenção e o tratamento de inúmeras doenças e enfermidades que têm causado considerável sofrimento e perdas.

Apesar disso, não nos podemos alhear da temática do risco, o qual se afigura como uma verdadeira constante na nossa Sociedade Mundial do Risco (44). Impõe-se, pois, uma atitude precaucional adequada, mormente que exija a observância estrita de um conjunto de requisitos materiais e procedimentais de diligência devida, propiciando uma adequada gestão do risco, ao mesmo tempo que se evita a tomada de medidas desadequadas ou excessivas que representem uma submissão a uma certa heurística do medo, necessariamente limitadora (ou até mesmo vulneradora) de direitos e liberdades dos indivíduos.

A saúde é, sem dúvida alguma, um dos bens mais valiosos de todo o ser humano, condição essencial à sua autorrealização e afirmação plena. Devemos, pois, trabalhar (em conjunto e de forma solidária!) para procurar que o maior número de pessoas possa alcançar o mais elevado nível de saúde possível. As novas tecnologias, nomeadamente as biotecnologias, podem, sem dúvida alguma, ajudar-nos nesse desiderato, cabendo-nos, porém, "perceber o que se está a passar e decidir o que fazer com elas, antes que elas o decidam por nós" (2). Sejamos, pois, cautos e cuidadosos, procurando sempre mobilizar a técnica para o bem comum, traçando um destino que se afigura risonho e, quem sabe, livre de tanta angústia e sofrimento.

\section{Referências}

1. Schwab K. A quarta revolução industrial (trad.). Portugal: LEVOIR; 2017.

2. Harari YN. Homo Deus: história breve do amanhã (trad.). 4. ${ }^{a}$ Edição. Amadora: Elsinore; 2017.

3. Loureiro J. Bios, tempo(s) e mundo(s): algumas reflexões sobre valores, interesses e riscos no campo biomédico. In: Andrade MC, Antunes MJ, Sousa AS, coordenadores. Estudos em homenagem ao Prof. Doutor Jorge de Figueiredo Dias. Vol IV. Coimbra: Coimbra Editora; 2009.

4. Rose S, Rose H. Can science be neutral?. Perspectives in Biology and Medicine. 1973, 16 (4): 605-624.

5. Nelkin D. Technological decisions and democracy: European experiments in public participation. California: Sage Publications; 1977.

6. Feito Grande L. El sueño de lo posible: bioética y terapia génica. Madrid: Comillas; 1999.

7. Kahn A. Société et révolution biologique. Paris: INRA Éditions; 1998. 
8. Loureiro J. Estatuto del nasciturus: una(s) mirada(s) europea(s) - vulnerabilidad, derecho(s) y el 'imperativo tecnocientífico'. In: Sánchez Sáez AJ, coordenador. La protección jurídica del nasciturus en el derecho español y comparado. Granada: Editorial Comares; 2018.

9. Talavera P. El actual paradigma subjetivista de la salud y sus repercusiones en su configuración como derecho humano y su cobertura universal. In: Santos JA, Albert M, Hermida C, editores. Bioética y nuevos derechos. Granada: Editorial Comares; 2016.

10. Sousa SA. Saúde pública, direito penal e 'novos riscos': um triângulo com lados desiguais. In: Gomes CM, coordenadora. Direito(s) dos riscos tecnológicos. Lisboa: AAFDL Editora; 2014.

11. Gostin LO, Taylor AL. Global Health Law: a definition and grand challenges. Public Health Ethics. 2008, 1 (1): 53-63.

12. Estorninho MJ, Macieirinha T. Direito da Saúde. Lisboa: Universidade Católica Editora; 2014.

13. Toebes B. International health law: an emerging field of public international law. Indian Journal of International Law. 2015, 55 (3): 299-328.

14. Santos BS. Os processos da globalização. In: Santos BS, coordenador. Globalização: fatalidade ou utopia. Porto: Editora Afrontamento; 2001.

15. Marques MR. A hipertrofia do presente no direito da era da globalização. Revista Lusófona das Humanidades e Tecnologias. 2009, 12: 121-132.

16. Woodward D, Drager N, Beaglehole R, Lipson D. Globalization and heath: a framework for analysis and action. Bulletin of the World Health Organization. 2001, 79 (9): 875-881.

17. Fortes P, Ribeiro H. Saúde global em tempos de globalização. Saúde Soc. 2014, 23 (2): 366375.

18. Conselho Empresarial para o Desenvolvimento Sustentável. Objetivos do Desenvolvimento Sustentável. Disponível em: https://www.ods.pt/ods/. [Acesso em: 31.out.2019].

19. Centro Regional de Informação das Nações Unidas. Objetivo 3 - Saúde de Qualidade. Disponível em: https://www.unric.org/pt/ods-link-menu/31972-objetivo-3-saude-dequalidade. [Acesso em: 31.out.2019].

20. World Health Organization. Promoting health in the SDGs: report on the 9th global conference for health promotion: all for health, health for all. 21-24 november 2016. Disponível em: https://www.who.int/healthpromotion/conferences/9gchp/shanghaiconference-report/en/. [Acesso em 28.out.2019]. 
21. Cardoso AP. As 10 piores ameaças à saúde global em 2019, segundo a OMS. DN Life. 21 jan 2019. Disponível em: https://life.dn.pt/as-10-piores-ameacas-a-saude-global-em2019-segundo-a-oms/saude/347962/. [Acesso em: 28.out.2019].

22. Loureiro J. Em busca de um direito da saúde em tempo de risco(s) e cuidado(s): sobre a incerteza do(s) nome(s) e da(s) coisa(s). In: Loureiro J; Pereira AD; Barbosa C, organizadores. Estudos em homenagem ao Prof. Doutor Guilherme de Oliveira. Vol. I. Coimbra: Almedina; 2016.

23. Loureiro J. Aegrotationis medicinam ab iure peto? Notas sobre saúde, a doença e o direito. Cadernos de Bioética. 2001, 25: 19-53.

24. Gostin LO. Global Health Law. USA: Harvard University Press; 2014.

25. Pereira AD. A emergência do direito da saúde. Cadernos Ibero-Americanos de Direito Sanitário. 2016, 5 (3): 180-200.

26. Rueger JP. Normative foundations of global health law. Georgetown Law Journal. 2008, 96 (2): 423-443.

27. Gostin LO, Sridhar D. Global health and the Law. The New England Journal of Medicine. 2014, 370 (18): 1732-1740.

28. Canotilho JJG, Moreira V. Constituição da república portuguesa anotada. Vol. I. 4. a Edição. Coimbra: Coimbra Editora; 2014.

29. Canotilho JJG. Para uma revisão da dogmática da jusfundamentalidade. In: Correia FA; Silva JC; Andrade JCV; Canotilho JJG; Costa JMC, coordenadores. Estudos em homenagem a António Barbosa de Melo. Coimbra: Almedina; 2013.

30. Abellán-García Sánchez F. Diagnostico genético embrionario y eugenesia: un reto para el derecho sanitario. Derecho Sanitario. 2007, 15 (1): 75-98.

31. Binet JR. Droit de la bioéthique. France: LGDJ - Lextenso Éditions; 2017.

32. Nussbaum M, Sen A. The quality of life. New York: Oxford University Press; 1993.

33. The President's Council on Bioethics. Beyond therapy: biotechnology and the pursuit of happiness. Washington D.C., October 2003.

34. Pyrrho M, Schrram FR. Nanotecnociência e humanidade. Coimbra: Imprensa da Universidade de Coimbra; 2016.

35. National Institutes of Health. Fact Sheet - Human Genome Project, outubro de 2010. Disponível em: https://report.nih.gov/nihfactsheets/viewfactsheet.aspx?csid=45. [Acesso em: 28.out.2019]. 
36. Melo HP. Implicações jurídicas do projeto do genoma humano. Coimbra: Gráfica de Coimbra II; 2007.

37. Santos HG, Pereira AD. Genética para todos: a prática, a ética, as leis e a sociedade. Lisboa: Gradiva; 2019.

38. Vieira LM. O conhecimento do genoma humano e suas implicações. Os Açores e o resto do mundo. O essencial no fim de século. Açores: Instituto Açoriano da Cultura; 1998.

39. Figueiredo E. Desagrilhoar Prometeu? Direito(s), genes e doença(s): Desafios constitucionais na era da engenharia genética [Tese]. Coimbra: Faculdade de Direito da Universidade de Coimbra; 2019.

40. Figueiredo E. Super-Man Syndrome: Vulnerability(ies) and Enhancement(s). Revista de Derecho y Genoma Humano. 2019, 50: 89-115.

41. Figueiredo E, Campos J. A proteção de dados genéticos em tempos de (r)evolução dos sistemas de saúde. Cadernos Lex Medicinae: saúde, novas tecnologias e responsabilidades. Vol. I. Coimbra: Instituto Jurídico/FDUC; 2019.

42. Syed S, Dadwal V, Martin G. Reverse innovation in global health systems: towards global innovation flow. Globalization and health. 2013, 9 (36): 1-2.

43. Bronze FP. Argumentação jurídica: o domínio do risco ou o risco dominado? (Tópicos para um diálogo pedagógico. In: Bronze FP, autor. Analogias. Coimbra: Coimbra Editora; 2012.

44. Beck U. Sociedade de risco mundial: em busca da segurança perdida (trad.). Lisboa: Edições 70; 2015.

45. Loureiro J. Constituição e Biomedicina - I [Tese]. Coimbra: Faculdade de Direito da Universidade de Coimbra; 2003.

46. Aragão A. Princípio da precaução: manual de instruções. Revista do CEDOUA. 2008, 2: $9-57$.

47. Loureiro J. Da sociedade técnica de massas à sociedade do risco: prevenção, precaução e tecnociência. In: AA.VV. Estudos em homenagem ao Prof. Doutor Rogério Soares. Coimbra: Coimbra Editora; 2001.

48. Moniz AR. Os direitos fundamentais e a sua circunstância: crise e vinculação axiológica entre o Estado, a sociedade e a comunidade global. Coimbra: Imprensa da Universidade de Coimbra; 2017.

49. Commission of the European Communities. Communication from the Commission on the precautionary principle. 2.fev.2000. Disponível em:

https://publications.europa.eu/en/publication-detail/-/publication/21676661-a79f-4153-b984aeb28f07c80a/language-en. [Acesso em: 30.out.2019]. 
50. Ferreira AE. A intangibilidade da identidade genética humana - um direito humano?. Lex Medicinae. 2011, 16: 107-125.

51. Melo AB. Crise e Crises: uma perspetiva jurídico-política. Temas de Integração. 2010, 29/30: 11-20.

Como citar este artigo:

Figueiredo EAS. Saúde global, inovação biotecnológica e risco(s). Cadernos Ibero-Americanos de Direito Sanitário. 2020 jan./mar.; 9(1): 36-58.

http://dx.doi.org/10.17566/ciads.v9i1.600 